DOI: http://dx.doi.org/10.19177/reen.v9e12016180-203

http://portaldeperiodicos.unisul.br/index.php/EeN/index

\title{
RESPONSABILIDADE SOCIAL E GOVERNANÇA CORPORATIVA EM UMA CONSTRUTORA
}

\section{SOCIAL RESPONSIBILITY AND CORPORATE GOVERNANCE IN A BUILDING COMPANY}

\section{RESPONSABILIDAD SOCIAL Y GOBIERNO CORPORATIVO EN UNA EMPRESA CONSTRUCTORA}

\section{Marilei Osinski}

Doutoranda em Engenharia e Gestão do Conhecimento na Universidade Federal de Santa Catarina (UFSC)

Endereço: R. Eng. Agronômico Andrei Cristian Ferreira, s/n, Trindade, CEP: 88040-900. Florianópolis, SC, Brasil

Telefone:(48) 3721-9000

E-mail: marileiosinski@gmail.com

\section{Darlan José Roman}

Doutor em Administração pela Universidade Federal de Santa Catarina (UFSC)

Professor no Programa de Mestrado Profissional em Administração da Universidade do Oeste de Santa Catarina (UNOESTE)

Endereço: R. Getúlio Vargas, n. 2125, Flor da Serra, CEP: 89600-000, Joaçaba, SC, Brasil

Telefone:(49) 3551-2000

E-mail: darlanroman@yahoo.com.br

\section{Mauricio Fernandes Pereira}

Pós-Doutorado em Administração pela Universidade de São Paulo (USP) e pela Universidade Técnica de Lisboa

Professor Associado do Departamento de Ciências da Administração da Universidade Federal de Santa Catarina (UFSC)

Endereço: R. Eng. Agronômico Andrei Cristian Ferreira, s/n, Trindade, CEP: 88040-900. Florianópolis, $\mathrm{SC}$, Brasil

Telefone:(48) 3721-9000

E-mail:mfpcris@gmail.com

Artigo recebido em 14/04/2015. Revisado por pares em 04/05/2015. Reformulado em 19/07/2015. Recomendado para publicação em 19/07/2015, por Ademar Dutra (Editor Científico). Publicado em 30/04/2015. Avaliado pelo Sistema double blind review. 


\section{RESUMO}

Esta pesquisa foi realizada em uma empresa de empreendimentos imobiliários da Grande Florianópolis a fim de analisar seu nível de Governança Corporativa, bem como seus atos de Responsabilidade Social. Esta pesquisa caracteriza-se como qualitativa e exploratória. Os dados primários foram coletados através da aplicação de um questionário estruturado e constatou-se, com base nas respostas obtidas e nos conceitos estudados, que a empresa possui atitudes superficiais de Responsabilidade Social, cumpre as leis vigentes, e tem alguns programas voltados à melhora, mas encontra-se em um grau inicial dessa prática. Quanto à Governança Corporativa, pode-se afirmar que a empresa não possui práticas relevantes.

Palavras-chave: Responsabilidade Social; Sustentabilidade; Governança Corporativa.

\section{ABSTRACT}

This research was held at a building company from the region of Florianopolis in order to analyze its corporate governance level, as well as their social responsibility actions. This research is designated as an exploratory and qualitative study. The primary data were collected out through an organized survey and it was concluded, based on the gathered answers and the previously studied concepts, the company takes shallow actions concerning social responsibility and even though it adheres to the law, also incorporates improvement programs, it is in an initial state of these actions. Regarding the corporate governance, it is possible state the company did not have any relevant actions.

Keywords: Social Responsibility; Sustainability; Corporate Governance.

\section{RESUMEN}

Esta investigación fue realizada en una empresa de desarrollo inmobiliario de la región de Florianópolis para analizar su nivel de Gobierno Corporativo, también sus actos de Responsabilidad Social. Esta investigación es caracterizada cómo cualitativa y exploratoria. Los datos primarios fueron colectados a través de la aplicación de un cuestionario estructurado y fue constatado, con base en las respuestas obtenidas y en los conceptos estudiados, que la empresa posee actitudes superficiales de Responsabilidad Social, cumple con las leyes vigentes y tiene algunos programas para mejora, pero se encuentra en un grado inicial de esa práctica. Acerca del Gobierno Corporativo, se puede decir que la empresa no posee prácticas relevantes.

Palabras-clave: Responsabilidad Social; Sostenibilidad; Gobierno Corporativo. 


\section{INTRODUÇÃO}

O contexto do século XX proporcionou uma mudança no mundo empresarial devido ao processo de globalização e inovações tecnológicas. Nesse contexto, a Responsabilidade Social passou a ser fundamental em organizações que têm como objetivo apresentar um diferencial diante do mercado e da sociedade - cada vez mais exigente - e se preocupam não só com o lucro, mas com as necessidades humanas. A Governança Corporativa, que tem na transparência um dos seus pilares, é utilizada pelas empresas socialmente responsáveis, podendo ser considerada relevante e indispensável para o bem-estar presente e futuro (INSTITUTO ETHOS, 2014).

Desta maneira, observa-se que uma empresa verdadeiramente comprometida com a Responsabilidade Social precisa abranger diversas práticas dentro de seu negócio, com o objetivo de torná-lo ético e virtuoso ao público interno e externo e ao ambiente que a circunda, promovendo um avanço da sociedade na qual está constituída. As organizações têm demonstrado grande interesse em apresentar soluções para os problemas ambientais, pois, além de ser um diferencial valorizado por muitos consumidores, há estratégias políticas impulsionando tais atitudes. Isto pode ser percebido em projetos como o Tratado de Kyoto, no qual os países têm o dever de reflorestar, devolvendo à natureza o que destruíram, tanto durante a extração de matéria-prima para a produção quanto com a emissão de gases poluentes (INSTITUTO ETHOS, 2014).

Segundo Bianchi et al. (2013), existe uma evidente demanda por ações sociais empresariais, principalmente em um panorama em que o Estado não é capaz de permitir, por si mesmo, o desenvolvimento sustentável, que é um processo urgente e amplo. Nesse contexto, demandas para que as empresas destinem recursos à Responsabilidade Socioambiental podem ser percebidos de diversos grupos de interesse, tais como clientes, fornecedores, governos e acionistas, dentre outros. Além disso, atualmente, a gestão socioambiental efetiva por parte de determinada organização pode ser considerada uma questão de sobrevivência empresarial.

Revista Eletrônica de Estratégia \& Negócios, Florianópolis, v.9, n.1, jan./abr. 2016. 
Entre as atitudes e comportamentos apresentados pelas empresas, na busca de sustentabilidade, nota-se, segundo o Instituto Ethos (2014), a presença de práticas diversas, como responsabilidade socioambiental, preocupação com o clima organizacional, treinamento e desenvolvimento de funcionários, cuidados com o meio ambiente, reciclagem, busca por meios mais econômicos de produção, redução de desperdícios, conscientização da importância dessas ações entre os próprios funcionários e consumidores em todos os setores de sua vida, entre outros. Esta preocupação com padrões de sustentabilidade influencia no desempenho organizacional, visto que exige gastos/ investimentos em pesquisa e, em contrapartida, pode trazer ganhos devido ao aumento de vendas e menores custos com a produção (caso haja maior aproveitamento de recursos e corte de desperdícios).

Neste sentido, esta pesquisa foi realizada em uma empresa de empreendimentos imobiliários, a fim de analisar se a mesma tem práticas de Responsabilidade Social e Governança Corporativa. Assim, o objetivo deste estudo foi apresentar as práticas de Responsabilidade Social e Governança Corporativa adotadas pela Construtora XYZ. O presente trabalho justifica-se por aprofundar o estudo da Responsabilidade Social Corporativa, bem como Governança Corporativa, que são tendências valorizadas e praticadas principalmente por grandes empresas. Ambas as tendências podem ser vistas como vantagem competitiva das organizações que a possuem, além de uma estratégia de marketing para captação de clientes e pela própria ética das organizações para com a comunidade que a integra, em uma perspectiva prática (BIANCHI et al. 2013).

Após esta seção de introdução, o presente estudo está estruturado da seguinte forma: revisão de literatura abordando a Responsabilidade Social e Governança Corporativa, tal como ocorrem no mundo e no Brasil, a conceituação e diferentes abordagens das mesmas, bem como alguns fatos acerca do Balanço Social; a próxima etapa consiste na metodologia, seguida do estudo de caso realizado. Finalmente, são apresentadas as considerações finais e as referências utilizadas na pesquisa em questão.

\section{RESPONSABILIDADE SOCIAL E GOVERNANÇA CORPORATIVA}


O aumento da importância da responsabilidade social organizacional é causado, de forma significativa, pela conscientização dos gestores de que as questões sociais são um fator de risco relevante, em algum grau, e são determinantes na criação de valor. Fatos como a criação de índices de avaliação da responsabilidade social são indicativos da atenção do mercado em relação a tal assunto (MIRANDA; AMARAL, 2010; KHAN; MUTTAKIN; SIDDIQUI, 2013).

Neste sentindo, Milani et al. (2012) afirmam que a BM\&F Bovespa desenvolveu índices, como Índice Carbono Eficiente (ICO-2), Índice de Ações com Governança Corporativa Diferenciada (IGC) e Índice de Ações com Governança Corporativa Diferenciada Trade (IGCT) com o intuito de mensurar o desempenho de empresas que adotam práticas de Governança Corporativa e Responsabilidade Social.

A criação de índices e outras tentativas de mensuração ocorrem, dentre outros fatores, pelo fato de a literatura apontar que a Responsabilidade Social Corporativa traz benefícios organizacionais em longo prazo. No entanto, Freguete, Nossa e Funchal (2015) questionam o fato de que nada se menciona a respeito dos potenciais benefícios da Responsabilidade Social Corporativa em curto prazo.

Além da possibilidade de gerar potenciais benefícios, a Responsabilidade Social Corporativa também se refere ao Desenvolvimento Sustentável por meio de relações justas com seus stakeholders. Nesse processo é abordado o desenvolvimento econômico, o meio ambiente e, ainda, a dimensão social (PRATES; PEDROZO; SILVA, 2015). As práticas de Governança Corporativa e Responsabilidade Social são chamadas por Milani et al. (2012) de práticas diferenciadas de gestão.

Ainda com relação aos índices supracitados, Milani et al. (2012) afirmam que é possível calcular o retorno financeiro das empresas que adotam práticas diferenciadas separadamente do retorno das demais empresas que, por sua vez, representam o mercado de maneira global. Rocha et al. (2011) explicam que empresas comprometidas com sustentabilidade e responsabilidade social buscam participar do Índice de Sustentabilidade Empresarial (ISE) da BM\&F Bovespa. O referido índice mede o retorno total de determinada carteira teórica composta por ações de organizações socialmente responsáveis.

Revista Eletrônica de Estratégia \& Negócios, Florianópolis, v.9, n.1, jan./abr. 2016. 
Porém, vale destacar, conforme Nogueira, Garcia e Ramos (2012), que não é apenas quanto ao que se refere ao retorno financeiro que as empresas podem adotar práticas de Governança Corporativa e Responsabilidade Social. No caso das instituições públicas, que devem disponibilizar as informações a todos os cidadãos, prestando contas de suas ações, adotar práticas de Governança Corporativa e Responsabilidade Social podem agilizar seu trabalho.

Quintero-Garzón et al. (2015) concordam com Nogueira, Garcia e Ramos (2012), em que a Governança Corporativa e Responsabilidade Social representam mais que apenas retorno financeiro. Os autores reconhecem que as organizações, além de produzir bens e serviços, são responsáveis pelos riscos que geram, não apenas aos seus trabalhadores, mas pela poluição ao meio ambiente.

O tema Responsabilidade Social, segundo Lima et al. (2011), tem permeado o campo dos estudos organizacionais. As empresas têm aprimorado ações de Responsabilidade Social e estas, por sua vez, ganham forma. Assim, à medida que tais práticas vão sendo sistematizadas, ocorrem mudanças nas organizações. Quando a sistematização não ocorre, o alinhamento da Responsabilidade Social à estratégia corporativa é inviabilizado. No entanto, Miranda e Amaral (2010) destacam que, como o objetivo da governança corporativa é criar regras e procedimentos que alinhem as ações dos gestores com os interesses dos proprietários, maximizam a riqueza.

\subsection{SURGIMENTO HISTÓRICO DA RESPONSABILIDADE SOCIAL NO MUNDO E NO BRASIL}

As empresas dos Estados Unidos foram pioneiras na prestação de conta ao público de suas ações sociais. Porém, a França foi o primeiro país a tornar obrigatória a prestação de contas dos investimentos sociais das empresas (SILVEIRA, 2003). No Brasil, na década de 70 e início de 80, com a transição para um estado democrático é que se pode identificar ações sociais empresariais. Devido ao grande crescimento de novas tecnologias, surgiu o processo que se denominou globalização econômica (RICO, 2004). O contexto empresarial brasileiro nos anos de 1980 apresentava um mercado em expansão, onde não existia a concorrência de produtos estrangeiros, mas que não apresentava novidades, nem se preocupava com os 
fatores de preservação do meio ambiente e não se sentia responsável pela qualidade de vida das comunidades a sua volta.

Já na década de 90 ocorreram grandes mudanças, devido às tecnologias de informação e a globalização, como o aumento da concorrência; oferta de produtos estrangeiros; cobrança dos direitos trabalhistas; clientes mais exigentes; a responsabilidade das empresas perante a preservação do meio ambiente. A empresa passa a ser reconhecida como um instrumento importante para o desenvolvimento social e crescimento individual. Diante de tantas mudanças e exigências, a empresa atual não pode pensar apenas em obter lucros, pois sua responsabilidade vai muito além, ou seja, é imprescindível ter um compromisso com as necessidades humanas, contribuindo, assim, para o bem de todos a sua volta (INSTITUTO ETHOS, 2014).

Difere-se, também, através deste conceito, a Responsabilidade Social do conceito de filantropia, sendo este último restrito ao público externo da organização, e sem a característica de ser propriamente sustentável, enquanto a Responsabilidade Social contempla a sustentabilidade nos âmbitos social, ambiental e também econômico, garantindo que a empresa possa estabelecer seu papel responsável dentro da sociedade sem colocar à custa sua economia, a manutenção do lucro e, portanto, sua própria existência (RICO, 2004; INSTITUTO ETHOS, 2014).

\subsection{SURGIMENTO HISTÓRICO DA GOVERNANÇA CORPORATIVA NO MUNDO E NO BRASIL}

A Governança Corporativa surgiu a partir de estudos antropológicos de como os grupos mais antigos se organizavam. Com esse estudo, concluiu-se que os tabus eram, de acordo com Bornholdt (2005), comportamentos esperados para o convívio em sociedade, o que hoje se expressa na forma escrita, por meio de leis, normas e códigos de ética.

Assim como nas antigas sociedades, é muito importante conhecer a cultura organizacional para que se implante um sistema de Governança Corporativa. Ela representa um conjunto de pensamentos que revela a identidade, bem como as relações dos grupos, e a forma como se orientam para se adaptarem ao ambiente externo. Este conjunto de 
pensamentos está "presente nos três níveis dos círculos da estrutura da cultura organizacional" (BORNHOLDT, 2005, p. 28). São eles:

1. O nível mais interno, intangível, imutável;

2. O segundo nível, o qual é invisível, e perceptível somente como reação do grupo em um estado de ameaça; e

3. O terceiro nível, que é visível, perceptível, e está expresso na forma de produtos, normas, organização.

Conforme Bornholdt (2005), na maioria dos casos, as organizações formais encaixam-se no nível externo (terceiro). A Governança Corporativa tem sua origem nos Estados Unidos, em 1980, fruto de um movimento criado pelos acionistas, os quais acreditavam que era importante a criação de novas regras que os defendessem dos excessos da diretoria executiva. Em outras palavras, a governança surgiu como um mecanismo de evitar o conflito de agência, o qual surge quando os interesses de uma parte dependem das decisões tomadas por outra. Em 1992, a Inglaterra tem seus primeiros tratados sobre Governança Corporativa.

No Brasil, os primeiros rumores de Governança Corporativa aparecem em 1995, com a criação do IBGC (Instituto Brasileiro de Governança Corporativa), juntamente com a CMV (Comissão de Valores Mobiliários), tendo como primeiro documento publicado o Código das Melhores Práticas de Governança Corporativa (BORNHOLDT, 2005).

Em 2000, a Bovespa criou os níveis de Governança Corporativa, isto é, regras que diferenciam as empresas de acordo com o grau de comprometimento com a Governança Corporativa, tendo como intuito o desenvolvimento do mercado de capitais brasileiro, visto que, em meados da década de 90 , este mercado passava por uma crise. O modelo nacional de Governança Corporativa é "baseado em incentivos fiscais para a aquisição de emissões (Fundo 157)" (CARVALHO, 2002, p. 25).

\subsection{CONCEITUAÇÃO E DIFERENTES ABORDAGENS DA RESPONSABILIDADE SOCIAL}


A Responsabilidade Social, segundo o Instituto Ethos (2014), pode ser entendida como a forma de gestão que mantém relações éticas e transparentes da empresa para com todos os públicos com os quais se relaciona, além do estabelecimento de metas empresariais que impulsionem o desenvolvimento sustentável da sociedade, preservando recursos ambientais e culturais, respeitando a diversidade e promovendo a redução das desigualdades sociais.

A Responsabilidade Social se faz cada vez mais necessária às empresas que querem apresentar diferencial para seus clientes e consumidores, perante o mercado de grande concorrência nacional e até mesmo mundial. Para Drucker (1993), a responsabilidade de uma empresa não consiste apenas no desempenho econômico, isto é, a organização tem plena responsabilidade pelo seu impacto sobre a comunidade e a sociedade. Greenan, Humphreys e Mcivor (1997, p. 210) afirmam que, "em vez de ver as exigências ambientais como uma ameaça, as empresas devem aproveitar a oportunidade para melhorar o seu desempenho ambiental, uma vez que os clientes veem isso como um atributo importante no momento da decisão de compra".

\subsection{CONCEITUAÇÃO E DIFERENTES ABORDAGENS DA GOVERNANÇA CORPORATIVA}

Com a globalização, o mercado tornou-se mais competitivo, exigindo que as empresas dessem rumos diferentes aos seus negócios. Uma demonstração de como isso vem ocorrendo é o caso das empresas familiares, as quais passaram a abrir seu capital para investidores, e a profissionalizar sua gestão, deixando que os cargos executivos fossem ocupados por pessoas sem laços de sangue (RODRIGUES, 2003; BORNHOLDT, 2005).

Assim, surgiu a necessidade de criar mecanismos para que a empresa não tivesse suas atividades voltadas somente aos interesses dos proprietários, mas que ela cumprisse um papel maior, tomando decisões que contemplassem todos os envolvidos, "primando pela melhoria da qualidade dessas relações numa proposta de transparência e gestão socialmente responsável" (RODRIGUES, 2003, p. 7). Esses mecanismos dão origem à Governança Corporativa. 
O IBGC conceitua a Governança Corporativa como um sistema capaz de administrar uma organização, envolvendo todos aqueles que nela estão interessados: proprietários e conselho administrativo. Estas práticas positivas de transparência na gestão têm "a finalidade de preservar e otimizar o valor da organização, facilitando seu acesso ao capital e contribuindo para a sua longevidade" (IBGC, 2014, p. 1). Já a CVM vê a Governança Corporativa como "um conjunto de práticas que tem por finalidade otimizar o desempenho de uma companhia ao proteger todas as partes interessadas, tais como investidores, empregados e credores, facilitando o acesso ao capital" (CVM, 2012, p. 1). Ainda, segundo a CMV, as práticas de Governança Corporativa são orientadas por princípios de: "transparência, equidade de tratamento dos acionistas e prestação de contas" (CVM, , p. 1).

É possível perceber que os dois órgãos (CVM e IBGC) têm uma abordagem semelhante sobre o tema; a CVM abrange um público maior que a Governança Corporativa deve contemplar, isto é, não só o alto escalão (investidores, proprietários e conselho), também demais stakeholders. O IBGC (2014) faz, ainda, uma divisão entre dois tipos de sistemas de Governança Corporativa em todo o mundo. O primeiro deles é o Outsider System, composto por acionistas que estão fora do contexto diário da organização, é um sistema tipicamente dos Estados Unidos e do Reino Unido, e tem as seguintes características:

- $\quad$ Estrutura de propriedade dispersa nas grandes empresas;

- $\quad$ Papel importante do mercado de ações na economia;

- Ativismo e grande porte dos investidores institucionais;

- $\quad$ Foco na maximização do retorno para os acionistas (shareholder oriented) (IBGC, 2014).

A segunda divisão/classificação feita pelo (IBGC, 2014) é o Insider System, composto por acionistas que têm grande parte das ações da organização, e que costumeiramente estão presentes na mesma, seja diretamente ou por meio de pessoas de sua confiança. Este sistema de Governança Corporativa é presente na Europa Continental e no Japão, e está orientado segundo alguns aspectos:

- $\quad$ Estrutura de propriedade mais concentrada;

- $\quad$ Presença de conglomerados industriais-financeiros;

Revista Eletrônica de Estratégia \& Negócios, Florianópolis, v.9, n.1, jan./abr. 2016. 
- Baixo ativismo e menor porte dos investidores institucionais;

- Reconhecimento mais explícito e sistemático de outros stakeholders nãofinanceiros, principalmente funcionários (stakeholder oriented) (IBGC, 2014).

\subsection{BALANÇO SOCIAL}

Atualmente existem novos conceitos acerca da existência das organizações, segundo os quais esta não pode se justificar exclusivamente pela capacidade que demonstram de gerar lucros a seus proprietários. É preciso preocupar-se em desenvolver e capacitar os funcionários, ajudar a comunidade e o meio ambiente. Comportamentos estes que muitas empresas já desenvolvem e repassam à população, que os classificam como mais importantes do que relatórios repletos de números e inacessíveis ao conhecimento popular (TINOCO, 2001).

Tinoco (2001) afirma, ainda, que, neste contexto, surge o Balanço Social - também chamado de Relatório de Sustentabilidade - que é um instrumento de gestão e de informação que visa a evidenciar, da forma mais transparente possível, informações econômicas e sociais, do desempenho das entidades, aos mais diferenciados usuários, entre estes os funcionários. O Balanço Social deve ser estruturado tendo o "dever de comunicar com exatidão e diligência os dados de sua atividade, de modo que a comunidade e os distintos núcleos que se relacionem com a entidade possam avaliá-la, compreendê-la e, se entenderem oportuno, criticá-la" (TINOCO, 2001, p. 14).

Tinoco (2001) afirma que a primeira vez que se mencionou a discussão da responsabilidade das organizações para com o público foi nos Estados Unidos, originada da insatisfação popular pelos conflitos gerados com a Guerra no Vietnã, entre as décadas de 60 e 70. Com a pressão popular externa e a interna sendo feita por um número considerável de acionistas dentro das próprias empresas, passou a ser obrigatória a justificativa do objetivo social das empresas, visando a uma melhora em sua imagem a partir de seus atos para com o meio ambiente.

Além do fim da guerra, passou-se a cobrar uma postura nova, mais ética, das organizações para com o público, sendo feitas exigências de preocupações além dos 
aspectos financeiros, como as relações sociais dentro e fora da mesma (TINOCO, 2001). Toda a coação fez surgirem as primeiras informações sociais, que passaram a ser publicadas juntamente com o balanço patrimonial, dando início à ideia de balanço social, que se estabeleceu posteriormente na França, em 1977, que evidenciava os recursos humanos. O balanço social deve conter informações como emprego; condições de higiene e segurança no trabalho; formação de mão de obra; relações profissionais; outras condições de vida dependentes da empresa, tais como alojamento, transporte da residência ao trabalho e viceversa; preservação do meio ambiente; e representatividade pública.

Sendo um instrumento necessário à gestão, Tinoco (2001, p. 30) apresenta os dois objetivos do balanço social, sendo o primeiro o de que, "no plano legal, fornece um quadro de indicadores a um grupo social, que após ter sido apenas um simples fator de produção, encontra-se promovido como parceiro dos dirigentes da empresa". E o segundo: "no plano de funcionamento da empresa, serve de instrumento de pilotagem no mesmo título que os relatórios financeiros. Os trabalhadores encontram-se assim associados à elaboração e à execução de uma política que os liga ao principal dirigente".

Conforme citado anteriormente, a França foi o primeiro país do mundo a implantar uma lei sobre o balanço social, denominada Lei no 77.769 de 12 de julho de 1977, mais conhecida como Rapport Sudreau. Segundo Tinoco (2001, p. 30), "essa lei foi posta em prática pela primeira vez em 1979, submetendo as empresas que possuíam 300 ou mais funcionários a publicar o balanço social”. Ela obteve méritos inegáveis, pois reconhecia, pela primeira vez e de forma institucional, a importância dos trabalhadores como usuários da informação contábil e social dentro da empresa.

Observando o sucesso obtido na França, outros países seguiram seu exemplo, como Alemanha, Espanha, Inglaterra, Suécia e Estados Unidos (TINOCO, 2001). Já o Brasil passou a discutir tal tema a partir de 1978, intermediado pelo Instituto de Desenvolvimento Empresarial - atual Fundação Instituto de Desenvolvimento Empresarial e Social (FIDES). O debate girava em torno da função e responsabilidades das empresas para o desenvolvimento da sociedade, que ocasionou a divulgação e incentivo para a elaboração desse relatório no país. O primeiro balanço social produzido em território brasileiro foi o da 
empresa Nitrofértil, do ramo químico, no ano 1984, tendo como foco seus próprios funcionários.

Um dos primeiros apoiadores da implementação do balanço social no Brasil foi o sociólogo Herbert de Souza, o popular Betinho, que organizou, na década de 80, a campanha Ação da Cidadania Contra a Fome, a Miséria e Pela Vida, promovida pelo Instituto Brasileiro de Análises Sociais e Econômicas (IBASE), o qual presidia. Contudo, apenas a partir da segunda metade dos anos 90 que as empresas brasileiras passaram efetivamente a publicar seus balanços sociais (INSTITUTO ETHOS, 2014).

Tendo em vista que a função do balanço social é reunir e divulgar o máximo de indicadores de transparência das atividades desenvolvidas pelas empresas, Tinoco (2001) mostra que sua elaboração deve estar em consonância com as áreas de departamento pessoal, de contabilidade e a de sistemas de informação, com o auxílio de inúmeros funcionários para a coleta de informações que alimentarão sua base de dados. No Brasil, há dois modelos de metodologia disponíveis aos empresários para a elaboração de seu balanço social, o modelo IBASE e o Global Reporting Initiative (GRI). O modelo IBASE apresenta as atividades internas e externas de Responsabilidade Social que são desenvolvidas pelas empresas através de uma planilha composta quase exclusivamente de dados quantitativos referentes a investimentos financeiros, sociais e ambientais.

O segundo modelo disponível para a construção do balanço social trata-se do GRI, o mais difundido e completo atualmente. Sua definição colabora com o engajamento das partes interessadas da organização, refletindo sobre seus principais impactos sociais e ambientais, assim como a estabelece quais serão seus indicadores e avalia como está a comunicação com o público de interesse. A escolha do modelo deve ser baseada nos objetivos que a organização pretende alcançar com a elaboração do balanço social. Ambos são de qualidade e fácil acesso por estarem disponíveis na internet. Além disso, algumas instituições, como o Instituto ETHOS, disponibilizam guias online para sua elaboração (INSTITUTO ETHOS, 2014).

\section{METODOLOGIA}

Revista Eletrônica de Estratégia \& Negócios, Florianópolis, v.9, n.1, jan./abr. 2016. 
Esta pesquisa caracteriza-se como qualitativa, tratando-se de um estudo exploratório. Assim, inicialmente, fez-se uma pesquisa por artigos científicos disponíveis nos principais indexadores (Scielo, Gales, Inform, Emerald, Wilson, Sage, Science Direct e Ebsco) da área de Administração do Portal Brasileiro da Informação Científica - periódicos da CAPES, com uma busca avançada por Responsabilidade Social e Governança Corporativa. Também foram utilizados livros referentes ao assunto, a fim de enriquecer a Fundamentação Teórica.

A empresa em questão é uma Construtora, que está no mercado desde julho de 1975. Como se pretende analisar as práticas de Responsabilidade Social e Governança Corporativa adotadas por essa empresa, primeiramente descreveu-se as supracitadas práticas, buscando apresentar seus benefícios para aumentar a competitividade e produtividade organizacional. Com base na Fundamentação Teórica foi elaborado um questionário a respeito dos temas em estudo. O referido questionário foi respondido pelo responsável pela área de Recursos Humanos, fornecendo, assim, os dados primários deste estudo.

O questionário aplicado na empresa foi dividido em algumas dimensões: a institucional, contendo perguntas gerais sobre a organização e sobre algumas possíveis práticas de Responsabilidade Social e Governança Corporativa; a social, cuja abordagem é quanto ao desenvolvimento do relacionamento da empresa com seus funcionários, clientes, fornecedores e sociedade, esclarecendo qual o papel que ela desempenha na comunidade em que está estabelecida, e como pratica a Responsabilidade Social sob estes aspectos; e por último, a dimensão ambiental, que tratou de como a empresa se relaciona com o meio ambiente, se possui certificações, programas de redução de água/luz e destinação certa dos resíduos, e se cobra uma postura adequada de seus fornecedores.

Após a aplicação do questionário fez-se a análise dos dados de forma descritiva, explicitando a realidade da empresa em estudo. Além disso, busca-se entender melhor como esses processos acontecem, agregando conhecimentos importantes para auxiliar a empresa na melhoria de seus processos de capacitação laboral. 


\section{ESTUDO DE CASO}

A Construtora $X Y Z$ é uma empresa, como mencionado anteriormente, de empreendimentos imobiliários, localizada na região metropolitana de Florianópolis. Tem mais de 100 edifícios residenciais e comerciais construídos ao longo deste período tanto na região continental, quanto na ilha de Florianópolis.

Quanto ao tamanho da empresa, ela é considerada de médio porte, de acordo com o número de colaboradores que possui. O SEBRAE (2014) utiliza o critério por número de empregados do IBGE para classificação do porte das empresas. Assim, empresas que tem de 100 a 499 empregados são consideradas de médio porte, como é o caso da Construtora XYZ, que conta com 218 empregados da própria construtora e, quando há necessidade, são contratados terceirizados para trabalhar nas obras. A organização ainda não tem sua visão e valores definidos, mas apresenta sua missão.

\subsection{INSTITUCIONAL}

Quando questionado sobre a existência de um código de ética que regesse a atuação dos funcionários dentro da empresa, bem como quais são as práticas que devem ser adotadas pelos mesmos enquanto parte da organização, o funcionário respondeu que ainda não há um manual, ou algo que contemple esta necessidade. Desta forma, é possível inferir que os funcionários sabem o que fazer e como fazer, bem como o que é e não é permitido pela Construtora $X Y Z$, de acordo com a vivência e com a experiência adquirida, apesar de não haver um documento formal.

Nos questionamentos sobre Responsabilidade Social e Governança Corporativa, foi abordado como os funcionários se preparam para isso, se a empresa oferece cursos que os eduque para o tema, isto é, que prepare os colaboradores para agir dentro das melhores práticas. A resposta não foi positiva: a empresa ainda não discute este tema com seus funcionários, da mesma forma que não publica um balanço social com as atividades e resultados de um período. Neste quesito, pode-se afirmar que a organização em questão não tem atitudes e comportamentos voltados à sustentabilidade, segundo o Tinoco (2001) e Instituto Ethos (2014). 


\subsection{DIMENSÃO SOCIAL}

Dentro deste tema, foi abordado sobre a comunicação entre os funcionários e a empresa, se existia incentivo à manifestação de críticas e sugestões ao processo produtivo, e à empresa como um todo. Descobriu-se que, como a construtora quer cada vez mais agradar e servir com mais qualidade seus clientes, muitas mudanças ocorrem, e algumas delas devido às sugestões dos colaboradores. O Instituto Ethos (2014) ressalta a importância da comunicação com o público de interesse.

Da mesma forma, quando questionada sobre os canais de comunicação existentes entre ela e os seus clientes, a Construtora $X Y Z$ alegou que os disponibiliza a fim de registrar manifestações (problemas), bem como para que os mesmos proponham soluções. Assim como a própria empresa informa seus clientes sobre o desfecho dos problemas apresentados.

As formas de comunicação mais utilizadas são:

- O contato pessoal, isto é, o cliente vai à empresa e conversa com um responsável para realizar uma solicitação;

- Contato telefônico;

- Via internet, pela página que a Construtora $X Y Z$ possui na rede, em que o cliente pode explanar o problema, e a empresa receberá por e-mail, conduzirá até a área técnica, e depois dará um retorno para o cliente.

Voltando aos aspectos do relacionamento com seus funcionários, foi questionado se a empresa possuía programas voltados para a promoção de saúde, segurança no trabalho e qualidade de vida dos mesmos. Atualmente a construtora mantém convênios com clínicas, laboratórios e farmácias, que podem ser utilizados pelos colaboradores da Construtora XYZ e seus dependentes. Quanto à segurança no ambiente de trabalho, por se tratar de uma construtora, esta é uma prática constante, e a empresa se dedica para que haja melhoria contínua das normas e hábitos de segurança.

Com relação aos funcionários, a empresa se preocupa com o bem-estar, tanto de seus colabores quanto de seus dependentes. Atualmente a empresa possui convênio com Revista Eletrônica de Estratégia \& Negócios, Florianópolis, v.9, n.1, jan./abr. 2016. 
uma clínica, cujo valor de uma consulta é de $\mathrm{R} \$ 60,00$, sendo custeado $50 \%$ pela empresa. Além disso, os funcionários têm direito a vale farmácia, e atualmente a empresa disponibiliza $\mathrm{R} \$ 70,00$ para cada colaborador. Neste caso, o colaborador somente pagará o valor que exceder os $\mathrm{R} \$ 70,00$. Há, ainda, o fornecimento de um ticket alimentação no valor de $\mathrm{R} \$ 440,00$ para cada colaborador fazer compras em supermercados sem desconto em folha. No final do ano é dado um presente para os filhos dos colaboradores que tenham menos de 12 anos de idade. A cada início de ano é comprado material escolar para os filhos dos colaboradores.

Ainda dentro do âmbito da qualidade de vida do colaborador, questionou-se a existência de cursos, treinamentos, ou seja, se há incentivo ao desenvolvimento profissional dos funcionários. A empresa mostrou-se empenhada em melhorar as técnicas de trabalho de seus colaboradores, visto que dispõe cursos (com empresas conveniadas ou não) para os mesmos, independentemente da área em que trabalham.

Nesses termos, conforme destacado por Tinoco (2001), a organização apresenta traços de Responsabilidade Social e Governança Corporativa por meio de atitudes voltadas à segurança no trabalho; formação de mão de obra; relações profissionais; outras condições de vida dependentes da empresa, tais como alojamento, transporte da residência ao trabalho e vice-versa.

Quando questionada sobre como lida com seus fornecedores em relação ao tratamento dos mesmos com seus próprios funcionários, a construtora informou que, por valorizar seus funcionários, ela prioriza os fornecedores que também tem esta mesma postura (tratamento com respeito e remuneração digna). Entretanto, nem sempre é possível manter este posicionamento, visto que a empresa não consegue controlar, vigiar seus fornecedores durante todo o tempo.

Para finalizar esta dimensão, questionou-se sobre a existência de certificação social da empresa (Empresa Cidadã, Empresa Amiga da Criança, etc.), e sobre o incentivo que ela dá aos funcionários para que realizem trabalhos voluntários, com vistas a colaborar com a sociedade. Infelizmente, a Construtora $X Y Z$ ainda não se encaixa nesses parâmetros sociais 
(não há selos de certificação), e ainda não desenvolve programas de serviços nãoremunerados com intuito de colaborar com o bem-estar social, entre os seus funcionários.

\subsection{DIMENSÃO AMBIENTAL}

Esta última dimensão abordou a relação que a empresa tem com a destinação de seus resíduos, e como eles impactam no meio ambiente, bem como a maneira que a mesma lida com seu papel na preservação dos recursos naturais. Tal questão é relevante, pois, segundo o Instituto Ethos (2014), a preservação do meio ambiente faz com que a empresa passe a ser reconhecida como instrumento importante para o desenvolvimento social e crescimento individual.

Seguindo estes parâmetros, questionou-se à empresa sobre a existência de licença ambiental vigente para que a empresa execute suas atividades. Observou-se que, a cada obra que a Construtora $X Y Z$ realiza, é necessário que consiga uma nova autorização para iniciar e dar continuidade à construção. Entretanto, ela ainda não possui selo de certificação ambiental (ISO 14000), e não adota práticas de redução de consumo de água, energia elétrica ou insumos do processo produtivo.

Apesar de não adotar as supracitadas práticas de conscientização ambiental, a empresa em questão se preocupa com o quadro social, ou seja, com a comunidade na qual está inserida, visando ao bem das pessoas. Atualmente são feitas ações voltadas para várias entidades como, por exemplo, um educandário situado em São José-SC. No entanto, Tinoco (2001) ressalta que, para a efetivação da Responsabilidade Social e Governança Corporativa, é preciso preocupar-se tanto em desenvolver e capacitar os funcionários quanto em ajudar a comunidade e o meio ambiente.

Dentro desta questão ambiental, abordou-se a construtora sobre a existência de um plano de gestão dos resíduos resultantes das suas atividades, e constatou-se que ela está se preocupando com isso. Segundo o funcionário responsável por responder aos questionamentos, de acordo com a vigência de uma nova lei, a Construtora XYZ está aperfeiçoando suas práticas para poder dar um fim adequado aos resíduos gerados. Uma medida que já é tomada é a reciclagem de materiais utilizados nas obras. Eles são vendidos, 
e o dinheiro arrecadado é utilizado para comprar presentes que são distribuídos aos funcionários no final de cada ano.

Outra política adotada pela organização é a de utilizar materiais que são ambientalmente corretos em suas obras, e também a de priorizar a compra de insumos com empresas que possuem selo ambiental. Segundo Bianchi et al. (2013) e Instituto Ethos (2014), a gestão socioambiental pode ser considerada uma questão de sobrevivência empresarial, da qual os fornecedores fazem parte. Cuidados com o meio ambiente, reciclagem, busca por meios mais econômicos de produção, redução de desperdícios e a conscientização da importância dessas ações são características da gestão socioambiental.

\section{CONSIDERAÇÕES FINAIS}

Ponderando a importância da Responsabilidade Social e da Governança Corporativa nas organizações, e a relevância dada a estes assuntos atualmente, o presente estudo buscou apresentar as práticas de Responsabilidade Social e Governança Corporativa adotadas pela Construtora $X Y Z$.

Pode-se afirmar que a Responsabilidade Social é uma forma de gerir as organizações, bem como sua relação com o público e o ambiente que a circunda, de maneira ética, transparente, visando ao desenvolvimento sustentável e à preservação dos recursos, respeitando, assim, todo o tipo de diversidade existente, seja ela cultural, social, ou ambiental. A Governança Corporativa preocupa-se com a transparência e a equidade nas relações organizacionais, isto é, funciona como um mecanismo que proporciona aos administradores a gestão para todos os envolvidos e interessados na empresa, evitando possíveis conflitos de interesse que possam surgir (INSTITUTO ETHOS, 2014).

Assim, pode-se assegurar que a Construtora $X Y Z$ revela algumas atitudes de Responsabilidade Social ao se interessar pela qualidade de vida dos seus funcionários, bem como de seus respectivos dependentes, ao preocupar-se com a qualidade de trabalho dos funcionários de seus fornecedores, e também pelas medidas que toma para a preservação ambiental, destinação correta dos resíduos, reaproveitamento de materiais e escolha correta de fornecedores (TINOCO, 2001; BIANCHI et al., 2013; INSTITUTO ETHOS, 2014). 
Porém, a empresa não tem atitudes simples citadas por Bianchi et al. (2013) e Instituto Ethos (2014), tais como plano de redução de consumo de água, energia ou insumos no processo produtivo e/ou administrativo que, apesar de serem atitudes pequenas e praticamente sem nenhum custo, com o tempo podem trazer bons resultados e vantagens, tais como gastos menores com tais despesas. Além disso, pelo potencial que a referida empresa possui, a mesma poderia realizar diversas outras atividades como, por exemplo, dar mais atenção aos fornecedores, atitude que a empresa revelou nem sempre conseguir estar atenta; buscar melhorias para conseguir os devidos selos de certificação ambiental, e ISO14000, visto que ela afirma, de certa forma, cobrar de seus fornecedores.

Portanto, é possível destacar que a Construtora $X Y Z$ ainda tem poucas medidas de Responsabilidade Social, e que está bastante atrelada ao que a lei a obriga fazer. Constata-se que a empresa está tentando se diferenciar, mas se encontra em um patamar baixo quanto ao desenvolvimento de práticas sustentáveis.

Quanto à Governança Corporativa, não foram identificadas práticas relevantes deste sistema na organização, tendo em vista que ela não tem objetivos claros explicitados por sua missão, visão e valores, ou um código de ética e conduta para permear o comportamento dos funcionários e o que deles se espera. Além disso, não se identificaram formas de ser transparente como, por exemplo, a publicação de um balanço social. Pode-se dizer que um passo que a empresa está dando para começar a implantar este mecanismo (Governança Corporativa) é quando ouve seus funcionários quanto as suas críticas e sugestões para melhoria dos processos operacionais e/ou administrativos (NOGUEIRA; GARCIA; RAMOS, 2012; MILANI et al., 2012).

Por fim, considera-se que, de forma geral, todas as atividades desenvolvidas por uma empresa interferem, de algum modo, no meio onde a mesma está inserida. Assim, a Responsabilidade Social, bem como a Governança Corporativa tornam-se temas extremamente importantes, visto que determinam diversos comportamentos e atitudes organizacionais. É indispensável a conscientização das pessoas e, consequentemente, das organizações para assuntos tão relevantes e difundidos atualmente (INSTITUTO ETHOS, 2014). 
Sugere-se à empresa analisada a busca por maior comprometimento no que diz respeito ao próprio planejamento, com a elaboração de sua visão e valores, sendo que esta possui apenas a missão consolidada atualmente. Seria interessante incluir valores voltados à preocupação ambiental, de modo que os colaboradores e clientes também sentissem esta conscientização. Ademais, a adoção de um código de ética seria importante, a fim de esclarecer os princípios organizacionais. Considera-se que as limitações da pesquisa se devem ao fato de a organização analisada não apresentar sua Responsabilidade Social e Governança Corporativa formalmente estruturadas, consistindo em atitudes isoladas.

Dentre as principais contribuições do estudo destacam-se a apresentação de informações detalhadas sobre as atitudes de uma construtora com relação ao meio ambiente, seus fornecedores e funcionários, visto que é uma empresa de um setor que gera resíduos e modifica o ambiente para executar suas obras. Além disso, o estudo apresenta informações atualizadas a respeito da Responsabilidade Social e Governança Corporativa.

Quanto às recomendações de futuros estudos, sugere-se a realização de uma pesquisa aprofundando apenas a Responsabilidade Social ou a Governança Corporativa, separadamente. Assim, poderia ser elaborada uma linha do tempo ilustrando cada fase do processo evolutivo, com características e detalhes. Além disso, poderia ser elaborado um estudo comparativo entre duas ou mais empresas do mesmo setor de atuação, destacando semelhanças e diferenças entre as mesmas.

\section{REFERÊNCIAS}

BIANCHI, Márcia; FAÉ, Mariana Domingues; GELATTI, Rosemary; ROCHA, João Marcos Leão da. A responsabilidade social como parte integrante da cultura organizacional em empresas socialmente responsáveis: análise de conteúdo entre a prática e o discurso. REEN - Revista eletrônica de estratégia \& negócios, Florianópolis, v. 6, n. 1, p. 160-191, jan./abr. 2013. Disponível em: <http://portaldeperiodicos.unisul.br/index.php/EeN/article/view/919/1093>. Acesso em: 14 nov. 2015.

BORNHOLDT, Werner. Governança Corporativa na Empresa Familiar: implementação e prática. Porto Alegre: Bookman, 2005.

CARVALHO, Antonio Gledson de. Governança corporativa no Brasil em perspectiva. Revista de Administração, São Paulo v. 37, n. 3, p. 19-32, jul./set. 2002. 
CMV - Comissão de Valores Mobiliários, Junho 2002. Recomendações da CVM Sobre Governança Corporativa. Disponível em: <http://www.cvm.gov.br/> Acesso em: 14 nov. 2015.

DRUCKER, Peter Ferdinand. Sociedade pós-capitalista. São Paulo: Pioneira, 1993.

FREGUETE, Lilian Marques; NOSSA, Valcemiro; FUNCHAL, Bruno. Responsabilidade social corporativa e desempenho financeiro das empresas brasileiras na crise de 2008. Revista de Administração Contemporânea, Curitiba, v.19, n. 2, mar./apr. 2015. Disponível em: <http://www.scielo.br/scielo.php?script=sci_arttext\&pid=S1415-65552015000200232>. Acesso em: 10 abr. 2016.

GREENAN, Kate; HUMPHREYS, Paul; MCIVOR, Ronan. The Green Initiative: Improving Quality and Competitiveness for Europeans SMEs. European Business Review, v. 97, n. 5, p. 208214, 1997.

IBGC - INSTITUTO BRASILEIRO DE GOVERNANÇA CORPORATIVA. Origem da Boa Governança. 2014. Disponível em: <http://www.ibgc.org.br/Secao.aspx?CodSecao=18> Acesso em: 13 nov. 2015.

INSTITUTO ETHOS. O Instituto Ethos. 2014. Disponível em: <http://www1.ethos.org.br/EthosWeb/pt/31/o_instituto_ethos/o_instituto_ethos.aspx>. Acesso em: 20 set. 2015.

KHAN, Arifur; MUTTAKIN, Mohammad Badrul; SIDDIQUI, Javed. Corporate Governance and Corporate Social Responsibility Disclosures: Evidence from an Emerging Economy. Journal of Business Ethics, v. 114, n. 2, p. 207-223. 2013. Disponível em: <http://www.contextus.ufc.br/index.php/contextus/article/view/305>. Acesso em: 13 dez. 2015.

LIMA, Teresa Cristina Aguiar; CABRAL, Augusto Cézar de Aquino; PESSOA, Maria Naiula Monteiro; SANTOS, Sandra Maria dos; NASCIMENTO, Debora Cardoso do. A institucionalização das práticas de responsabilidade social: Um Estudo na Companhia de Água e Esgoto do Ceará. Contextus - Revista Contemporânea de Economia e Gestão. v. 9, n. 1, jan/jun 2011. Disponível em:

<http://www.contextus.ufc.br/index.php/contextus/article/view/305>. Acesso em: 13 dez. 2015.

MILANI, Bruno; RIGHI, Marcelo Brutti; CERETTA, Paulo Sérgio; DIAS, Valéria da Veiga. Práticas de Sustentabilidade, Governança Corporativa e Responsabilidade Social afetam o risco e o retorno dos investimentos? Revista de Administração da UFSM, Santa Maria, v. 5, Edição Especial, p. 667-682, Dez. 2012. Disponível em: <http://cascavel.ufsm.br/revistas/ojs2.2.2/index.php/reaufsm/article/view/6946>. Acesso em: 13 dez. 2015.

MIRANDA, Rubens Augusto; AMARAL, Hudson Fernandes. Governança Corporativa socialmente responsável como estratégia de criação de valor. Revista Estudos do CEPE, Santa Cruz do Sul, n. 32, p. 5-31, jul./dez. 2010. Disponível em: 
<http://online.unisc.br/seer/index.php/cepe/article/view/1629/1237>. Acesso em: 13 dez. 2015.

NOGUEIRA, Maria da Graça Saraiva Saraiva; GARCIA, Tania Elisa Morales; RAMOS, Maria da Graça Gomes. Governança corporativa, responsabilidade social corporativa: a visão de atores de uma instituição de ensino superior - IES Federal. Revista GUAL, Florianópolis, v. 5, n. 3, p. 222-244, dez. 2012. Disponível em:

<https://periodicos.ufsc.br/index.php/gual/article/view/1983-4535.2012v5n3p222/23672>. Acesso em: 13 dez. 2015.

PRATES, Caroline; PEDROZO, Eugênio; SILVA, Tania. Corporate Social Responsibility: A Case Study in Subsidiaries from Brazil and China. Journal of technology management \& innovation, Santiago, v.10, n. 3, out. 2015. Disponível em: <http://www.scielo.cl/scielo.php?pid=S0718-27242015000300014\&script=sci_arttext >. Acesso em: 10 abr. 2016.

QUINTERO-GARZÓN, Martha L.; CARRIÓN-GARCÍA, Andrés; JORDÁ-RODRÍGUEZ, Ma. Aurora; RODRÍGUEZ-CÓRDOBA, Ma. del Pilar. Corporate Social Responsibility and the EFQM excellence model as a frame work for integration of management systems in organizations. Ingeniería y competitividad, Cali, v.17, n. 1, jan./jun. 2015. Disponível em: <http://www.scielo.org.co/scielo.php?script=sci_arttext\&pid=S0123-30332015000100002>. Acesso em: 10 abr. 2016.

RICO, Elizabeth de Melo. A Responsabilidade Social empresarial e o Estado: uma aliança para o desenvolvimento sustentável. 2004. Disponível em:

$<$ http://www.scielo.br/scielo.php?script=sci_arttext\&pid=S0102-88392004000400009>. Acesso em: 11 set. 2015.

ROCHA, Irani; NASCIMENTO, Sabrina do. SILVA, Júlio Orestes da; SOUZA, Rony Petson Santana de; MACHADO, Denise Del Prá Netto. A evidenciação da cultura organizacional voltada para a responsabilidade ambiental. REEN - Revista eletrônica de estratégia e negócios, Florianópolis, v. 4, n. 1, p. 108-132, jan./jun. 2011. Disponível em: <http://portaldeperiodicos.unisul.br/index.php/EeN/article/view/510/632>. Acesso em: 19 nov. 2015.

RODRIGUES, Ana Tércia L. Governança Corporativa: quando a transparência passa a ser uma exigência global. IX Convenção de Contabilidade do Rio Grande do Sul. Agosto, 2003. Disponível em: <http://www.ccontabeis.com.br/conv/t04.pdf >. Acesso em: 14 nov. 2014.

SEBRAE. 2014. Critérios de classificação de empresas: EI - ME - EPP. Disponível em: <http://www.sebrae-sc.com.br/leis/default.asp?vcdtexto=4154>. Acesso em: 19 nov. 2015.

SILVEIRA, Maria do Carmo Aguiar da Cunha. O Que é Responsabilidade Social Empresarial? 2003. Disponível em:

<http://www.fiec.org.br/artigos/social/responsabilidade_social_empresarial.htm>. Acesso em: 11 out. 2015. 
TINOCO, João Eduardo Prudêncio. Balanço Social: uma abordagem da transparência e da responsabilidade pública das organizações. São Paulo: Atlas, 2001. 